http://dx.doi.org/10.1590/0102-311XCO050814

Moisés Goldbaum

Faculdade de Medicina, Universidade de São Paulo, São Paulo, Brasil. mgoldbau@usp.br

\section{A view based on experience in Public Health}

I am honored by the invitation to join the debate on this essay by Reinaldo Guimarães. I do so gladly, attempting to momentarily set aside the references from the scientific literature, drawing rather on my experience as an activist in the field of Public Health. First, I wish to highlight the privilege of having shared initiatives with Guimarães, with whom I learned and assimilated significant and important knowledge for designing and implementing policies in science, technology, and innovation in health (ST \& I/H). Such knowledge allowed him to give significant impetus to the development of ST \& I/H in Brazil.

The author's fascinating presentation of a theme (whose complexity he acknowledges) raises various issues that are too extensive to cover fully in the allotted space. I will therefore focus on two issues in the hopes of shedding further light on his premises.

The first issue relates to the research/graduate studies/research vector. I agree with his points reaffirming the positions by Eunice Dur- 
ham concerning the relations between research activities and graduate studies. However, this interpretation can be framed differently. Capes has successfully promoted the development of a modern graduate studies system, an unequivocal example of the possibilities and existence of Brazil's domestic capabilities in establishing effective public policies. An analysis of the process of accrediting (or recommending) programs shows that the best programs are those with strong and consolidated structures for scientific research. The examples in the field of Public Health are impressive. I will not list them here, but a consultation of previous triennial evaluations confirms the results, both in terms of the initial proposals and in the positive and upward trends (note: it is beyond the scope here to discuss the need for some revisions in the evaluation process). Furthermore, as a consequence of this development, these programs reaffirm the quote by Carlos Chagas Filho with their inestimable role in training highly competent and qualified faculty and researchers, besides producing relevant knowledge in their lines of research. Meanwhile, if one were to acknowledge the need to change directions in this relationship between research and graduate studies, the broad expansion of graduate studies programs in Brazil may not have materialized, given that many such programs only have (or had) an incipient tradition in research.

I believe that Guimarães would not disagree with this analysis. If such is the case, the most immediate, instigating, and challenging proposition lies in the creation (in this relationship between research and graduate studies) of spaces where society can express its priorities and establish the proposed vector "society/research/ graduate studies", with an emphasis on the first two, in my understanding. As the author points out quite well, organized society's participation in this process is still practically nonexistent in Brazil. This reveals another kind of complexity that merits the attention of policymakers in the development of ST \& I. In the particular case of health, Guimarães cites a prime example of which he was the key protagonist. I am referring to the initiative sparked by the creation (in 2003) of the Secretariat for Science, Technology, and Strategic Inputs under the Brazilian Ministry of Health and the reorganization of the Department of Science and Technology (DECIT). The definition of the Brazilian Ministry of Health as the leading player in health research priority-setting and in the decisive support for such priorities produced the first and substantial steps towards designing a framework in which the relationship between society and research gained consistency. Health is one of the sectors in which social participation made the greatest strides, with the implementation of Health Councils at the three levels of government (Federal, State, and Municipal). As we all know, the councils are social representation structures with oversight and control powers in relation to health policies and thus with ascendency over ST \& I/H policies (due to the position in the National Conferences on ST \&I/H that "Policy for Science, Technology, and Innovation in Health is a component of National Health Policy"). Despite the need for improvements in the social control processes, in principle the basis exists for proceeding with the successful program to support the development of ST \&I/H. I believe that this initiative of seeking to transform and provide the Ministry of Health with the leading role in ST \& I/H (an initiative reproduced in some States based on stimulus from the Federal government itself) has become prime material for extending our knowledge on the complexities surrounding social participation in relation to scientific research. Obviously, the inherent dynamics and rules of the science sector's development cannot be violated or overlooked in this process, nor were they in the action by the Brazilian Ministry of Health (action that merits real and definitive institutionalization). Full and comprehensive respect for scientific merit creates prospects for a solid link with social relevance, the understanding of which has not accompanied the existing domain in the analysis of merit in research projects. I see this as one of the central issues in the analysis proposed by Guimarães, and I believe that unraveling this issue is the key to elucidating the obscure points identified by him.

Another point for analysis refers to the executive graduate studies programs. According to its original conceptualization, this modality of human resources training responds more adequately to the needs for training executive professionals in different sectors of society. It applies perfectly to the case of health, and more specifically to the area of Public Health. Introduced somewhat late, it responds to the needs of services institutions (both government and private) for epidemiological surveillance, health surveillance, and pharmaceutical care, among others. The obligatory reflection relates to the path taken by executive graduate studies. Thus, conceived to meet the demand for health executives, such programs (I contend) should respond to orders placed by institutions demanding such executives, in agreement with the supply (e.g., in the case of Public Health, the demand generated by the Brazilian Ministry of Health and by State and Municipal Health Secretariats). However, unless I am mistaken, this is not what we have seen in the establishment and accreditation of programs. 
Despite following the proper guidelines prescribed for executive graduate studies programs (e.g., the possibility of including faculty members that do not necessarily have academic degrees, in addition to broader monographs and lack of funding from Capes), the supply is still generally the main determinant in the program's formatting. There are usually no contracts with the demand (which should be responsible for fully funding its training needs). Students' participation can be individualized and not linked to the demand's proposals. This makes the executive programs more similar to academic programs, a trend that may explain the resistance looming in some scientific communities. I highlight these points because I believe that if the executive graduate studies modality presents a consistent link between demand and supply, it becomes an important element for understanding one of the obscure points detected by Guimarães, namely the society/research/graduate studies vector. And this applies not only to the health sector, but encompasses all areas of knowledge, to the extent that it provides fertile ground for designing the link between academia, industry, and services in the quest for maturity in the field of innovation. 